\title{
AMBIENTES DIGITAIS CONFIÁVEIS PARA PRESERVAÇÃO HOLÍSTICA DE DOCUMENTOS ARQUIVÍSTICOS
}

\section{TRUSTED DIGITAL ENVIRONMENTS FOR HOLISTIC PRESERVATION OF ARCHIVAL RECORDS}

\author{
Amanda Keiko Higashia \\ Fabiana Ciocheta Mazuco ${ }^{b}$ \\ Henrique Machado dos Santos ${ }^{c}$ \\ Daniel Flores d
}

\begin{abstract}
RESUMO
Introdução: Este estudo aborda a problemática dos documentos arquivísticos em ambiente digital, os quais são dotados de complexidades e especificidades que impactam diretamente na preservação e no acesso. Logo, necessitam de sistemas confiáveis que garantam sua capacidade probatória, para que possam ser utilizados como evidências. Objetivos: Sendo assim, discorre-se sobre a relação entre as cadeias de custódia e preservação, tendo em vista a construção de um ambiente confiável capaz de preservar os documentos arquivísticos e manter sua autenticidade no longo prazo com garantia de acesso. Metodologia: Para tanto, realizou-se um levantamento bibliográfico composto essencialmente por livros, publicações técnicas, teses e artigos científicos recuperados através da ferramenta de pesquisa Google Scholar. Busca-se explicar a interdependência entre as cadeias de custódia e de preservação, tendo como pano de fundo o modelo Records Continuum. Obtém-se um artigo de revisão assistemática/narrativa. Resultados: Observou-se que as cadeias de custódia e de preservação possuem elevado nível de interdependência quando abordadas em ambiente digital. Assim, há necessidade de manter uma linha ininterrupta entre 0 Sistema Informatizado de Gestão Arquivística de Documentos e o Repositório Arquivístico Digital Confiável. Igualmente, as ações de preservação devem ser pensadas na gestão e até mesmo antes da produção documental, tal pressuposto

a Mestre em Patrimônio Cultural pelo Programa de Pós-Graduação em Patrimônio Cultural da Universidade Federal de Santa Maria (UFSM). Arquivista analista na Universidade Regional do Noroeste do Estado do Rio Grande do Sul (UNIJUÍ) e Museu Antropológico Diretor Pestana (MADP). E-mail: amandahigashi@gmail.com.

b Mestre em Patrimônio Cultural pela Universidade Federal de Santa Maria (UFSM). Arquivista Diretora do Arquivo Público Municipal de São Francisco de Assis, RS. E-mail: fabianamazuco@gmail.com.

c Mestre em Patrimônio Cultural e bacharel em Arquivologia pela Universidade Federal de Santa Maria. Arquivista da Coordenação de Arquivo Geral da Universidade Federal do Rio Grande (UFRG). E-mail: henrique.hms.br@gmail.com.

d Doutor em Metodologías y Líneas de Investigación en Biblioteconomía y Documentación pela Universidad de Salamanca. Docente do Departamento de Ciência da Informação da Universidade Federal Fluminense (UFF). E-mail: dfloresbr@gmail.com.
\end{abstract}


converge com os fundamentos do Records Continuum. Conclusões: Portanto, a interdependência das cadeias de custódia e preservação aliada à necessidade de preservar os documentos de forma pró-ativa aponta para uma reformulação dos acervos. Isto requer tratamento documental holístico, capaz de prevenir e minimizar os efeitos da obsolescência tecnológica.

Descritores: Preservação digital. Confiabilidade. Cadeia de custódia documental. Cadeia de preservação documental.

\section{INTRODUÇÃO}

O avanço tecnológico influencia diretamente a comunicação e 0 compartilhamento de informações nas organizações, tal fenômeno acarreta o aumento da produção de documentos digitais. Para manter o caráter arquivístico dos documentos, surge a necessidade de desenvolver um ambiente digital confiável que comporte todo o ciclo de vida, desde a gênese, perpassando, tramitação, preservação e acesso. Assim, observa-se que a autenticidade dos arquivos digitais, depende de uma cadeia de custódia ininterrupta que comporte todo o ciclo de vida dos documentos, de modo que seja amparada por uma cadeia de preservação.

A cadeia de custódia documental é o ambiente pelo qual perpassa o ciclo de vida dos documentos, e que possui um custodiador responsável por proteger os princípios e as funções preconizadas pela Arquivística (FLORES; ROCCO; SANTOS, 2016). Trata-se de um modelo conceitual derivado da Arquivística e do Direito, que pressupõe políticas e normalização, abrangendo responsabilidades pela guarda e proteção documental por instituições e agentes confiáveis. Logo, entende-se que para a presunção de autenticidade dos documentos arquivísticos digitais, a cadeia de custódia exige normalização e sistemas informatizados que orientem a gestão e a preservação digital no longo prazo em consonância com a teoria Arquivística.

Já a cadeia de preservação trata-se de um sistema de controles que contempla todo o ciclo de vida dos documentos, tendo em vista assegurar sua autenticidade ao longo do tempo (BRASIL, 2008). Portanto, a cadeia de preservação é um modelo de ações e procedimentos técnicos, definidos a priori em consonância com políticas organizacionais que vislumbram a manutenção 
da infraestrutura tecnológica. Com isso, é possível manter registros de metadados de preservação, bem como, a cadeia de custódia.

Diante do exposto, o presente estudo tem por objetivo, relacionar as cadeias de custódia e preservação tendo em vista a manutenção de um ambiente confiável que garanta a autenticidade dos documentos arquivísticos digitais. Tal relação é contextualizada no âmbito do Records Continuum e preconiza a interoperabilidade entre os sistemas informatizados responsáveis pela gestão, preservação e acesso à informação.

Para tanto, o método utilizado parte de um levantamento bibliográfico composto essencialmente por livros, publicações técnicas, teses e artigos científicos. Por conseguinte, os artigos são recuperados por meio da ferramenta de pesquisa Google Scholar, buscador capaz de localizar materiais em diversas fontes de informação. Os dados coletados são analisados pelo método qualitativo, que se caracteriza pela subjetividade da interpretação, e a discussão dos resultados segue a lógica dedutiva. A reflexão proposta caracteriza este estudo como pesquisa explicativa, que analisa a interdependência entre as cadeias de custódia e de preservação, tendo como pano de fundo a perspectiva do Records Continuum (GIL, 2010; LUNA, 1997; SILVA; MENEZES, 2005; VOLPATO, BARRETO, UENO, VOLPATO, GIAQUINTO; FREITAS, 2013).

Com isso, obtém-se um artigo de revisão com caráter assistemático/narrativo que parte de uma temática aberta, guiada pelos referenciais da Arquivística e busca estabelecer relações entre a custódia confiável, a preservação digital e o Records Continuum (CORDEIRO, OLIVEIRA, RENTERÍA; GUIMARÃES, 2007). A abordagem proposta neste estudo bibliográfico possibilita compreender a necessidade da preservação digital e da confiabilidade serem pensadas durante todo o ciclo de vida dos documentos, e até mesmo, antes de sua produção.

\section{AUTENTICIDADE DO DOCUMENTO ARQUIVÍSTICO EM AMBIENTE DIGITAL}

A autenticidade dos documentos arquivísticos digitais requer evidências 
internas e externas, advindas da diplomática: a fixidez dos elementos extrínsecos (forma física ou aparência documental) e intrínsecos (conteúdo). Logo, o ponto de divergência entre documento analógico e digital está na aplicação da preservação desde a origem. As constantes mudanças tecnológicas tornam os ambientes digitais vulneráveis, fato que dificulta sustentar a capacidade de que o documento é genuíno e livre de alterações (ROGERS, 2016).

A fragilidade dos documentos produzidos em ambiente digital envolve sua condição complexa e específica, decorrente da natureza digital que facilita a obsolescência tecnológica e o uso inadequado, pois estes registros são facilmente alterados, duplicados, convertidos, e até mesmo falsificados sem deixar vestígios aparentes (SANTOS; FLORES, 2015). Tendo em vista a obsolescência dos componentes de hardware, software e do próprio suporte, ressalta-se a importância da interferência humana para manter da presunção de autenticidade dos documentos arquivísticos digitais no longo prazo (SANTOS; FLORES, 2017).

Observa-se que o ambiente digital é dotado de instabilidade de modo que os documentos arquivísticos nele armazenados correm um risco contínuo de serem perdidos ou adulterados. A abordagem do documento arquivístico digital deverá então, considerar princípios e especificidades da Arquivística como, por exemplo, proveniência, indivisibilidade, organicidade, naturalidade e autenticidade.

A autenticidade do documento arquivístico digital requer que a gestão seja estruturada por um sistema informatizado para implementar políticas e procedimentos que controlem a produção, transmissão, manutenção, avaliação, destinação e preservação dos documentos. Com isso, estima-se garantir a proteção contra acréscimo, supressão, alteração, uso e ocultação indevidos. $O$ documento arquivístico deve refletir corretamente o que foi comunicado, decidido ou a ação implementada, além de conter os metadados necessários para documentar a ação. Dessa forma, será capaz de apoiar as atividades administrativas, bem como prestar contas sobre as mesmas (BRASIL, 2011a).

Para documentos digitais, questões como forma fixa e conteúdo estável 
assumem um viés típico de sua natureza dinâmica. Portanto, certo grau de variação na forma e no conteúdo dos documentos digitais não compromete sua capacidade documental, logo, poderá ser entendida como uma variabilidade limitada (RONDINELLI, 2011; 2013). Ou seja, podem-se definir quais são as características essenciais que deverão ser preservadas, de modo que seja possível determinar se os documentos sofreram um nível de alteração tolerável.

As alterações na apresentação documental podem ser aceitas mediante regras e padrões bem definidos. As recomendações e procedimentos a serem adotados devem auxiliar na identificação das características essenciais para manter autenticidade dos documentos arquivísticos digitais, de modo que viabilize a representação estável do conteúdo, a identificação do contexto administrativo e autoridades envolvidas na produção e preservação (INTERPARES, 2007b).

Observa-se que para preservar a informação digital há necessidade de alterá-la, bem como ponderar sobre o impacto de tais alterações. Assim, além da preservação digital manter os requisitos para garantir a autenticidade deverá reunir informações adicionais, por meio de metadados, para identificar alterações.

No âmbito da diplomática há características que tornam o documento arquivístico autêntico: forma fixa, conteúdo estável, relação orgânica, contexto identificável, ação e cinco atores envolvidos (autor, redator, destinatário, originador e produtor). Assim, além das funções e atividades representadas pelo documento de arquivo, os conceitos diplomáticos que sustentam sua materialidade documental estão diretamente ligados à autenticidade, seja ele analógico ou digital (RONDINELLI, 2011; 2013).

A autenticidade é composta pela integridade e pela identidade documental, registrada pelo produtor. Observa-se que a identidade do documento se relaciona com a preservação do conteúdo, apresentação estável, além dos elementos que identificam o propósito de produção (BRASIL, 2011a). Portanto, a integridade relaciona-se à preservação dos elementos de materialidade do suporte, considerados extrínsecos, tendo em vista que os documentos apresentam-se completos e não sofreram nenhum tipo de 
corrupção ou alteração não autorizada e/ou não documentada (BRASIL, 2008; DURANTI, 2015).

A aplicação dos princípios arquivísticos de proveniência, organicidade, unicidade, indivisibilidade e cumulatividade corroboram com a manutenção da identidade. Para tanto será preciso implementar um programa de gestão arquivística de documentos (BELLOTTO, 2002). Dessa forma, é possível estabelecer um conjunto de procedimentos técnicos que orientem as ações em fase corrente e intermediária (produção, tramitação, uso, avaliação e arquivamento), tendo em vista a sua eliminação ou recolhimento ao arquivo permanente (BRASIL, 2008).

Nessa perspectiva, observa-se que a autenticidade dos documentos arquivísticos em ambiente digital está condicionada ao ambiente informatizado no qual os documentos são armazenados. Logo, deve-se garantir a confiabilidade do sistema desde a produção, perpassando sua tramitação e uso, até que ocorra o recolhimento para guarda permanente. Tais aspectos apontam para a necessidade de uma cadeia de custódia ininterrupta que agrega confiabilidade ao ciclo de vida dos documentos arquivísticos.

\section{CADEIA DE CUSTÓDIA PARA MANUTENÇÃO DA AUTENTICIDADE}

A autenticidade do documento arquivístico está ligada à sua transmissão, preservação e custódia, bem como, a todos os agentes envolvidos no ciclo vital dos documentos. Logo, para ser autêntico deve manter a mesma forma quando produzido, para que assim, permaneça com o mesmo grau de confiabilidade (BRASIL, 2011a; RODRIGUES, 2004). Nesse sentido, a autenticidade deve ser preservada durante o ciclo de vida, de modo que não há como elevar o seu nível, apenas mantê-lo. Uma vez que os sistemas deixam de ser confiáveis, os documentos armazenados podem ter sua autenticidade questionada.

A custódia documental consiste na responsabilidade jurídica pela guarda e proteção dos arquivos, independente do vínculo de propriedade/proveniência. Este custodiador deve assegurar a preservação dos documentos com garantia de autenticidade, para que possam ser utilizados como fontes de informação 
confiáveis (BRASIL, 2005).

A custódia documental está relacionada com a posse e a responsabilidade, de modo que deve ser delegada para custodiadores confiáveis, ou seja, pessoas ou instituições que não tenham interesses diretos em destruir ou adulterar os documentos. Destaca-se que a escolha do custodiador confiável torna-se ainda mais proeminente quando se tratam de documentos arquivísticos em ambiente digital, tendo em vista a facilidade de alterá-los sem deixar vestígios.

Ressalta-se que o conceito de cadeia de custódia no contexto arquivístico tem origem com Jenkinson (1922) reconhecendo que o valor da prova documental ocorre pelo caráter único, autêntico e imparcial dos arquivos. Por conseguinte Flores, Rocco e Santos (2016) observam que a presunção da autenticidade na tradicional visão de Jenkinson (1922) é condicionada à cadeia de custódia ininterrupta, que envolve o ciclo de vida dos documentos arquivísticos. Todavia, essa visão tradicional da custódia não é suficiente para garantir a autenticidade dos documentos arquivísticos digitais, em decorrência de sua complexidade tecnológica e especificidade arquivística.

Sendo assim, a manutenção da confiabilidade torna-se inerente ao início da cadeia de custódia, tendo em vista que a produção dos documentos ocorre no momento ou imediatamente após a ação executada por pessoas diretamente envolvidas na condução das atividades e devidamente autorizadas; com o grau de completeza requerido tanto pela organização, quanto pelo sistema jurídico (BRASIL, 2011a). O conceito de custódia está relacionado à responsabilidade, guarda, tutela, cuidado, posse, controle e proteção. Destaca-se que a custódia não implica em título legal de propriedade, logo, limita-se a responsabilidade de proteção. Com isso, o custodiador não corresponde necessariamente ao produtor (SILVA, 2015; 2017).

A custódia per si não garante que as condições de guarda serão adequadas, que os documentos permanecerão autênticos e não sofrerão nenhuma intervenção que altere suas características essenciais. Porém, a mesma constitui-se requisito jurídico do arquivo, pois define quem tem autoridade sobre os documentos, como é exercida essa proteção e preservação. 
O estabelecimento da custódia inicial ao produtor, com base no Manual dos Holandeses, é condição inerente ao conceito de arquivo (instituição arquivística), pois deve haver um responsável pela guarda dos documentos. Tal atribuição caracteriza a instituição arquivística, diferenciando-a de um conjunto qualquer de documentos. Assim, a finalidade da custódia no âmbito da Arquivística é manter os inter-relacionamentos entre os documentos de modo que possam atestar suas ações (SILVA, 2015; 2017).

A custódia adequada dos documentos deve ser realizada por um custodiador confiável, ou seja, entidade ou indivíduo que tenha expertise e atribuições legais para exercer tal atividade. Logo, isso implica na capacidade de manter os princípios arquivísticos, as funções, bem como garantir a manutenção da autenticidade.

A cadeia de custódia implica na guarda documental em todo o seu ciclo vital, embora haja diferenças entre a custódia atribuída ao produtor e à instituição arquivística. Uma delas consiste na custódia intelectual, que remete à retenção documental para ação ou referência, inerente à existência do documento enquanto arquivístico. Outro ponto a ser ressaltado corresponde à proteção física e tem relação com a perspectiva do preservador disponibilizar o material custodiado. Ademais, nessa concepção há a custódia legal, de responsabilidade jurídica sobre propriedade como: produção, autoria, acesso e custódia física (SILVA, 2015; 2017).

$\mathrm{Na}$ abordagem da custódia preconizada por Jenkinson (1922), a transmissão da custódia de uma entidade para outra, não significa que a custódia tenha sido interrompida. Tal fato se sustenta, pois o custodiador original dos documentos representa uma pessoa conectada com a administração que os produziu, logo, as funções administrativas e a documentação podem ser transferidas para uma autoridade totalmente diferente, sem que 0 acervo perca suas características (SILVA, 2015; 2017).

No caso dos documentos digitais, a ausência de plataformas interoperáveis para gestão, preservação em longo prazo e acesso, irá causar a interrupção desta cadeia. Consequentemente, perde-se confiabilidade em relação aos sistemas informatizados, de modo que a autenticidade dos 
documentos em custódia será duvidosa.

Observa-se que o contexto registrado pelos sistemas informatizados é essencial para preservar as características dos documentos arquivísticos digitais, representam assim, o modelo de gestão arquivística (organicidade, unicidade, confiabilidade, autenticidade e acessibilidade), aliado a fundamentos da diplomática (forma fixa e conteúdo estável) (INNARELLI, 2015).

Logo, para que não haja ruptura da cadeia de custódia, é preciso implementar uma política de preservação que esteja em conformidade com os fundamentos da Arquivística. Igualmente, as plataformas de gestão, preservação e acesso devem ser interoperáveis a fim de evitar a perda de informações essenciais para a presunção da autenticidade.

\section{CADEIA DE CUSTÓDIA E CADEIA DE PRESERVAÇÃO EM AMBIENTE DIGITAL}

A cadeia de custódia ininterrupta tem seu delineamento, além das políticas arquivísticas e do custodiador confiável, contemplando assim, a infraestrutura e os sistemas que criam um ambiente em conformidade com a teoria arquivística. Com isso, é possível preservar de forma segura os documentos digitais e as ações registradas no âmbito da gestão e da preservação, garantindo a sua autenticidade (FLORES; ROCCO; SANTOS, 2016; LUZ, 2018; LUZ; FLORES, 2016; SOUZA; SOARES; FERNANDES; MELO, 2017).

A cadeia de custódia consiste em uma linha ininterrupta ou contínua de custodiadores, iniciada pelo produtor até seu legítimo sucessor, assegurando que os documentos permanecem autênticos desde a produção (BRASIL, 2012). Igualmente, contribui para garantir a autenticidade e a confiabilidade com relação à fixidez do documento, comportando assim, a produção, o uso, até à destinação final, seja eliminação ou guarda permanente (LUZ; FLORES, 2016).

A linha ininterrupta está associada à visão tradicional, a arquivística custodial, onde a instituição produtora é a mesma responsável pela preservação. Já o conceito de custódia contínua ocorre quando uma instituição delega a 
custódia documental para um custodiador confiável, o qual possui competência jurídica e técnica para exercer tal responsabilidade. Essa abordagem é denominada de arquivística pós-custodial, pois permite alteração da custódia com objetivo de salvaguardar os documentos.

Tendo em vista a complexidade e a vulnerabilidade dos documentos digitais, entende-se que é fundamental identificar aqueles que possuam valor permanente. Logo, a garantia de longevidade deve ser compartilhada entre os produtores e os preservadores (MACNEIL, 2016). Nessa perspectiva é preciso definir um custodiador confiável, responsável pelo processo de preservação. Ademais, este deve demonstrar que não tem motivos para alterar ou permitir que outros os alterem os documentos arquivísticos. Sendo assim, o custodiador confiável deve cumprir com todos os requisitos necessários para preservar documentos autênticos no longo prazo (INTERPARES 2007a).

Observa-se que o arquivo tem como característica ser um lugar designado à proteção e guarda dos documentos. No caso dos documentos arquivísticos em ambiente digital, esse local se constitui por meio dos sistemas informatizados e da infraestrutura tecnológica (SILVA, 2015; 2017). Portanto, a manutenção de uma custódia confiável e ininterrupta é fundamental para os documentos arquivísticos digitais, logo, isso implica na relação entre os sistemas informatizados para gestão e preservação (FLORES; ROCCO; SANTOS, 2016).

Para os casos em que houver alteração da cadeia de custódia, os metadados atuam como validadores dessa transição, pois permitem registrar informações referentes ao período de responsabilidade de cada custodiador. Igualmente, servem para comprovar a autenticidade dos documentos recebidos, tornando viável a alternativa pós-custodial para documentos digitais.

Em ambiente digital, as evidências de transação dos documentos estão estruturadas em sistemas de gestão e preservação. Assim, constituem um conjunto de plataformas, com a responsabilidade de custodiar os documentos arquivísticos digitais (LUZ, 2018). Dessa forma, pode-se entender a cadeia de custódia em ambiente digital como:

Um conjunto sequencial de ações a serem desempenhados por um produtor e um custodiar de documentos. Eles atuam com a 
aplicação da arquivística integrada e incorporam a cadeia de custódia ininterrupta como estratégia de reforço de confiabilidade e autenticidade documental e por profissionais da informação (LUZ, 2018, p. 98).

A linha de custódia ininterrupta subsidia a manutenção da autenticidade, bem como a preservação digital em longo prazo dos documentos arquivísticos. Isso comporta desde o início do ciclo de vida dos documentos até sua destinação, para que assim seja possível manter a identidade arquivística e as características diplomáticas intrínsecas e extrínsecas dos documentos.

As cadeias de custódia e preservação atuam em conjunto, de modo que a cadeia de preservação assegura e protege registros que são pertinentes à cadeia de custódia (LUZ; FLORES, 2016). Logo, há uma interdependência entre as cadeias de custódia e preservação no que se refere ao ciclo de vida dos documentos de arquivo (VOUTSSÁS MÁRQUEZ, 2010). Caso haja falha na cadeia de preservação, a confiabilidade documental torna-se questionável. Sendo assim, o modelo da cadeia de preservação estabelece que:

Os documentos de arquivo digitais devem ser cuidadosamente manejados ao longo de sua existência para assegurar que sejam acessíveis e legíveis ao longo do tempo deixando sua forma, conteúdo e relações intactas até o ponto necessário para adquirir sua contínua confiança como documento de arquivo (VOUTSSÁS MÁRQUEZ, 2010, p.158-159, tradução nossa).

Ressalta-se que a preservação digital tem a preocupação de manter os documentos interpretáveis em diferentes plataformas de hardware e software desde sua origem, sendo necessário realizar estudos sobre as mídias, cópias de segurança e estratégias como a migração e a emulação. Tais ações se reafirmam como necessárias, pois a preservação digital transcende o tempo, as plataformas tecnológicas e os suportes de armazenamento (SANTOS; FLORES, 2017).

Observa-se a necessidade de considerar a preservação digital com relação aos fatores: culturais e sociais; tecnológicos e documentais; legais e econômicos. Os fatores culturais e sociais possuem enfoque humanista, de modo que possibilitam objetivos do contexto social, como, por exemplo, o acesso à informação no longo prazo. Já os fatores tecnológicos e documentais tem 
enfoque nas tecnologias da informação, nas telecomunicações, além das especificidades da disciplina Arquivística. Por fim, os fatores legais e econômicos visam a contextualização dos projetos conforme aspectos jurídicos e financeiros tendo em vista os interesses de produtores e preservadores em relação aos custos envolvidos (VOUTSSÁS MÁRQUEZ, 2010).

Observa-se que a preservação digital perpassa diferentes esferas. Assim, parte-se de soluções tecnológicas mediadas por políticas de preservação, as quais recebem amparo financeiro com o intuito de retroalimentar a segurança da organização. Ademais, estes esforços entregam um valor social agregado, que é a preservação da memória propriamente dita.

Dentre os principais tópicos a serem considerados na preservação de documentos digitais, destacam-se: segurança da informação; transparência nos serviços governamentais; custos associados à preservação; desenvolvimento e inclusão de metadados adequados para recuperar a informação; integração das funções arquivísticas na cadeia de preservação; e mecanismos de acesso (VOUTSSÁS MÁRQUEZ, 2010).

Sendo assim, para garantir uma gestão confiável e segura será preciso envolvê-la em uma cadeia de custódia ininterrupta, capaz de monitorar todas as ações proferidas sobre a documentação. Diante da complexidade dos documentos digitais faz-se indispensável o uso de mecanismos de controle a fim de comprovar a sua autenticidade. Ademais, surge a necessidade de dispor de plataformas que facilitem o acesso à informação para o público.

\section{DO AMBIENTE DE GESTÃO AO AMBIENTE DE PRESERVAÇÃO}

No contexto brasileiro, recomenda-se que a gestão de documentos seja realizada por um Sistema Informatizado de Gestão Arquivística de Documentos (SIGAD). Este irá controlar o ciclo de vida documental por meio de um conjunto de procedimentos e tecnologias da informação que poderá ser implementado por um único software ou por um conjunto de softwares (BRASIL, 2011b).

Nessa perspectiva, recomenda-se o uso do Modelo de Requisitos para Sistemas Informatizados de Gestão Arquivística de Documentos (e-ARQ Brasil). 
Este modelo propõe um conjunto de requisitos para implementar o SIGAD, elaborado a partir de padrões internacionais. Assim, tem por objetivo adicionar a confiabilidade ao ambiente de gestão, a fim de garantir o acesso a documentos autênticos. Logo, trata-se de uma especificação dos requisitos a serem cumpridos pelo sistema de arquivos da organização produtora/recebedora de documentos (BRASIL, 2011a).

Ressalta-se que o SIGAD contempla especificidades necessárias à gestão arquivística, seja em relação aos documentos digitais ou analógicos. Portanto, o SIGAD poderá gerenciar documentos analógicos após a captura e 0 armazenamento de seus respectivos representantes digitais (COSTA, 2018).

Manter um sistema de arquivos confiável presume proteger os ambientes de gestão e de preservação, os quais compõem o ciclo de vida dos documentos. Dessa forma, os documentos arquivísticos são avaliados e consequentemente recebem uma destinação final, seja a eliminação ou o recolhimento ao arquivo permanente.

Com isso, surge a necessidade do SIGAD interoperar com um ambiente de preservação igualmente confiável, constituindo a cadeia de custódia ininterrupta para proteger os documentos. Neste contexto, a Resolução ํo 43, de 04 de setembro de 2015 do Conselho Nacional de Arquivos (CONARQ), recomenda o uso do Repositório Arquivístico Digital Confiável (RDC-Arq), principalmente para os documentos em fase permanente.

O RDC-Arq pode contemplar as fases corrente, intermediária e permanente. De modo que será capaz de preservar os documentos de forma autêntica além de garantir o acesso no longo prazo. Ressalta-se que o uso em fase corrente e intermediária se dá por questões de preservação, essencialmente para casos específicos, quando há documentos com longa temporalidade, elevado nível de complexidade e de sensibilidade. Tais documentos, por exemplo, podem ter diversos componentes digitais ou serem sigilosos (BRASIL, 2015).

Observa-se que a cadeia de custódia confiável deve comportar todo o ciclo de vida dos documentos arquivísticos, se estendendo desde o ambiente de gestão até o ambiente de preservação. Deste modo, mantém-se uma linha 
ininterrupta entre SIGAD e RDC-Arq. Assim, Salienta-se que para a implementação do SIGAD é recomendado seguir o padrão e-Arq Brasil, já para o RDC-Arq é essencial manter conformidade com o Open Archival Information System (OAIS).

O modelo OAIS trata-se de uma norma International Organization for Standardization (ISO), doravante 14721:2012, que foi traduzida para o Brasil pela Associação Brasileira de Normas Técnicas (ABNT), tornando-se uma Norma Brasileira Recomendada (NBR), doravante ABNT/NBR 15472:2007, Sistema Aberto de Arquivamento de Informação (SAAl).

Este modelo de referência comporta uma série de funções para preservar a informação, isso inclui questões como: admissão de conteúdos, armazenamento arquivístico, gerenciamento de dados, acesso e disseminação. Ademais, o OAIS aborda a migração de informações digitais para novos formatos e suportes, bem como os modelos de dados usados para representar a informação (ABNT/NBR 15472:2007; CCSDS, 2012; ISO 14721:2012).

Pode-se entender o OAIS como uma organização de pessoas e sistemas, que assumiu o compromisso de preservar um determinado conjunto de informações no longo prazo. Igualmente, deve-se garantir que tais informações são acessíveis a comunidade designada, ou seja, aos consumidores entendidos como público-alvo (THOMAZ, 2004).

Ressalta-se que os padrões como o modelo OAIS, e outros criados no âmbito do Consultative Committee for Space Data System (CCSDS), são revisados em períodos de no máximo cinco anos a partir da data de sua publicação. Com isso, o CCSDS irá determinar três situações: permanecer em vigor sem alterações; ser alterado para refletir o impacto de novas tecnologias, requisitos ou procedimentos; ou ser desativado/cancelado (CCSDS, 2012; ISO 14721:2012).

De forma geral, o modelo OAIS/SAAI consiste em um conjunto de fluxos de informação necessários para que o RDC-Arq possa preservar os documentos digitais custodiados. Para facilitar as trocas de informação com os ambientes externos, estabelece três tipos de pacotes de informação: Pacote de Informação para Submissão (Submission Information Package - SIP); Pacote de Informação 
para Arquivamento (Archival Information Package - AIP) e Pacote de Informação para Disseminação (Dissemination Information Package - DIP).

Os pacotes de informação são recipientes que encapsulam as informações de conteúdo (documentos digitais) e a sua respectiva informação de representação (metadados). Com isso, é possível reunir todas as informações consideradas pertinentes para preservar e garantir a autenticidade das informações de conteúdo (MÁRDERO ARELLANO, 2008).

Os pacotes (SIP, AIP e DIP) são essenciais para estabelecer os fluxos de informação com as entidades externas ao OAIS, que são o produtor e 0 consumidor. Neste contexto, produtor submete seus documentos por meio do pacote SIP ao OAIS; o administrador do OAIS irá transformar este pacote em um AIP para manter conformidade com os requisitos de preservação em longo prazo; igualmente, o administrador irá converter o AIP em DIP para melhor atender as demandas do consumidor.

Um RDC-Arq deve manter conformidade com o modelo OAIS, para tanto o projeto de implantação e manutenção requer o trabalho compartilhado entre os profissionais de arquivo e de tecnologia da informação. Com isso, estima-se suprir as necessidades tecnológicas, além de manter conformidade com as técnicas e os princípios preconizados pela Arquivística.

Quando os documentos são transferidos por meio de sistemas ou pessoas ocorre a alteração da cadeia de custódia, logo, a responsabilidade pela preservação e manutenção da autenticidade é igualmente transferida ao novo custodiador. Portanto, é essencial manter mecanismos de monitoramento que registrem as diversas ações executadas nos ambientes de gestão e preservação documental para controlar a alteração da custódia.

Sendo assim, o controle sobre transferências e recolhimentos dos documentos arquivísticos digitais requer questões como: o monitoramento de procedimentos utilizados; a verificação da autoridade das partes envolvidas (produtor e preservador); e análise dos documentos arquivísticos para avaliar se correspondem à lista de transferência/recolhimento (INTERPARES, 2007b).

As cadeias de custódia e de preservação ressaltam a ideia de continuidade do tratamento dos documentos, especialmente em ambiente digital, 
tendo em vistas as vulnerabilidades as quais estão expostos. Portanto, a tradicional ideia de separação entre ambiente de gestão e preservação necessita ser reformulada, visto que as ações de preservação de longo prazo já devem ser planejadas antes mesmo da produção dos documentos.

\section{A PERSPECTIVA DO RECORDS CONTINUUM}

Os fundamentos do Records Continuum são extremamente pertinentes na preservação de documentos arquivísticos digitais, pois os mantêm autênticos desde a produção, tendo em vista o seu reuso pela sociedade (SILVA, 2015; 2017). Ademais, este modelo considera a cadeia de custódia e a preservação aplicadas aos documentos digitais sob o prisma da Arquivística (LUZ, 2018).

De imediato o Records Continuum desperta atenção por não fazer uso da tradicional cisão entre os ambientes de gestão (arquivo corrente e intermediário) e preservação (arquivo permanente). Igualmente, o mesmo ocorre com as sete funções arquivísticas, que passam a ser aplicadas conforme as necessidades do acervo, e não mais de forma linear.

Observa-se que o Records Continuum se opõe ao tradicional ciclo de vida dos documentos, tendo o pressuposto de que a gestão documental é um processo contínuo. Além disso, considera a possibilidade de uso dos documentos por diferentes indivíduos da sociedade (VOUTSSÁS MÁRQUEZ, 2010). Esse modelo trata-se da administração consistente e coerente de processos, antes mesmo da produção dos documentos. Isso contempla desde a concepção de sistemas informatizados até a preservação e reuso dos documentos arquivísticos (EASTWOOD; HOFMAN; PRESTON, 2008).

Desse modo, os sistemas de negócios podem ser implementados em diversos níveis da organização, sendo eles: estratégico, transversal, tático e na infraestrutura operacional (LUZ, 2018). No entanto, um fator que adiciona complexidade à moderna gestão de documentos é a dispersão dos documentos em diversos sistemas informatizados que compõem o sistema de negócios das organizações.

Logo, para a manutenção da autenticidade dos documentos arquivísticos 
digitais por meio das cadeias de custódia e de preservação, deve-se estruturar diferentes sistemas a fim de representar o modelo Records Continuum. Isso contempla o registro de informações nos ambientes de negócio, gestão, preservação e acesso. Conforme Upward (1997), o modelo possui quatro dimensões funcionais que preconizam:

- Identificar os responsáveis pelos atos, e assim, criar e capturar as evidências destes;

- Dispor de sistemas para manutenção dos documentos produzidos e recebidos, a fim de vincular os metadados necessários para manter o vínculo arquivístico, bem como para a sua identificação;

- Atender as demandas documentais de uma entidade jurídica por meio de um esquema contínuo de manutenção, que incorpora os sistemas e o acervo, com a finalidade de constituir uma memória corporativa/institucional;

- Prover o acesso às demandas da sociedade por meio da manutenção dos documentos, e assim, assegurar seu uso para fins de responsabilidade social da instituição produtora, bem como para preservação da memória coletiva (UPWARD, 1997).

Na primeira dimensão do modelo Records Continuum é preciso detalhar os sistemas que compõem o ambiente de negócio nos diversos níveis de interesse organizacional. Dentre tais sistemas podem-se citar: portal corporativo; ferramentas de apoio à inovação; bases de conhecimento; mapas do conhecimento; Groupware/E-mail; Enterprise Resource Planning (ERP); Sistemas especializados (recursos humanos, financeiro, produção, etc); Customer Relationship Management (CRM); Lead Relationship Management (LRM); Workflow; e Gestão Eletrônica de Documentos (GED) (LUZ, 2018).

Os sistemas de negócio devem ser projetados para registrar todos os trâmites desde a produção dos documentos. Igualmente, devem planejar os conjuntos de metadados para fazer dos documentos, evidências confiáveis. Sendo assim, o ambiente de negócio necessita de requisitos semelhantes aos utilizados por um sistema de gestão arquivística (MCKEMMISH, 1997 apud EASTWOOD; HOFMAN; PRESTON, 2008). 
A segunda dimensão, caracterizada pela aplicação das funções arquivísticas, que tem início na captura dos documentos para trâmite, uso e arquivamento até seu destino final (eliminação ou recolhimento de guarda permanente). Logo, requer um sistema que contemple tais ações. Salienta-se que nesta fase, o documento ainda possui elevado nível de consultas e compõem processos em andamento (LUZ, 2018). Ademais, neste ambiente ocorrem os primeiros tratamentos com relação à preservação de documentos, por meio do SIGAD.

A terceira dimensão constitui o ambiente de custódia definitiva do arquivo, para fins de preservação contínua por meio de um RDC-Arq que protege os documentos e suas informações relacionadas (LUZ, 2018). Dessa forma, é fundamental que o RDC-Arq esteja em conformidade com o modelo OAIS, tendo em vista a estrutura de metadados requerida para registrar procedimentos técnicos de preservação, especificar direitos de acesso, de modo a corroborar com a manutenção da autenticidade dos documentos (FLORES; ROCCO; SANTOS, 2016).

Já a quarta dimensão representa a disseminação, que poderá ser apoiada por uma plataforma acoplada ao RDC-Arq que irá disponibilizar os DIPs por meio das interfaces de mediação (sites, portais, redes sociais e outros). Assim, a plataforma de acesso torna-se o local de pesquisa, de modo que não permitirá acesso direto aos AIPs armazenados no ambiente de preservação do RDC-Arq (LUZ, 2018).

Ressalta-se que integrar a manutenção dos documentos arquivísticos, conforme preconizada por este modelo, corrobora com questões como: proteger a proveniência; apoiar a responsabilidade; e constituir a memória e a identidade. Com isso, o contexto torna-se dinâmico e a manutenção pró-ativa, de modo que os documentos são planejados antes mesmo de serem produzidos e capturados (MCKEMMISH,1997 apud EASTWOOD; HOFMAN; PRESTON, 2008).

Inevitavelmente, o planejamento será a peça-chave para obter êxito nas ações de preservação digital. Logo, a manutenção das cadeias de custódia e preservação dependerá de ações que comportem todo o ciclo de vida documental. Sendo assim, a abordagem do Records Continuum contribui para a 
manutenção pró-ativa dos documentos arquivísticos, de modo que entrelaça as cadeias de custódia e preservação envolvendo-as no ciclo vital.

Nesse contexto, será preciso implementar um conjunto de metadados para garantir a autenticidade dos documentos. Tais documentos devem possuir atributos necessários com relação ao seu conteúdo, contexto e estrutura, para que assim, possam atestar atividades realizadas, tornando-se evidências (MCKEMMISH, 1997 apud EASTWOOD; HOFMAN; PRESTON, 2008). Desse modo, os documentos são produzidos com capacidade probatória e previamente classificados pelos metadados, de modo que já é possível avaliá-los com base em seu valor.

As dimensões do Records Continuum permitem a representação das cadeias de custódia e preservação em ambiente digital, além de manter as especificidades dos documentos arquivísticos. As responsabilidades pela custódia são pré-estabelecidas e gerenciadas em diferentes plataformas e modelos, para assim, garantir que os documentos possam ser utilizados como evidências (LUZ, 2018).

Nessa perspectiva, o Modeling Digital Records Creation, Maintenance and Preservation: Modeling Cross-domain Task Force Report foi elaborado para incorporar funcionalidades do Records Continuum na gestão arquivística e na preservação digital (EASTWOOD; HOFMAN; PRESTON, 2008). Para tanto, utilizaram-se os modelos Business-Driven Record Keeping (BDR) e Chain of Preservation (CoP).

Observa-se que o modelo BDR derivou de projetos, padrões e normas como: International Research on Permanent Authentic Records in Electronic Systems (InterPARES), Clever Metadata Project and Records Continuum Research, Designing and Implementing Recordkeeping Systems (DIRKS), ISO 15489, ISO 23081-1 e ISO 14721. Assim, o BDR aborda o negócio da organização além de sua produção documental, incorporando assim, seu contexto jurídico, econômico e cultural. Assume-se como foco, tanto os documentos necessários às atividades imediatas, como aqueles de interesse histórico à sociedade (EASTWOOD; HOFMAN; PRESTON, 2008).

Dessa forma, é possível atender a dinâmica do ambiente societário e 
envolver a gestão corporativa/ambiente de negócio, aplicando assim, o conceito de continuidade advindo da Austrália. Consequentemente, estima-se contemplar o contexto mais amplo de interesse da sociedade, não se limitando apenas às questões burocráticas.

Já o modelo CoP mantém a linha de custódia ininterrupta entre as ações proferidas nos ambientes de gestão e preservação. Tendo em vista que tais ambientes comportam as tradicionais sete funções arquivísticas, pode-se afirmar que o CoP contempla todo o ciclo de vida dos documentos arquivísticos. Dessa forma, a convergência entre os modelos CoP e BDR resulta em um sistema de informação que preconiza a preservação de longo prazo, além de manter conformidade com os princípios e as funções arquivísticas.

Destaca-se que o Records Continuum tem se configurado como uma alternativa ao ciclo vital dos documentos, sendo capaz de agregar uma visão holística das atividades arquivísticas que se contrapõe à linearidade do modelo tradicional. Essa abordagem não faz distinção entre arquivo corrente, intermediário e permanente, de modo que os arquivistas estão envolvidos no processo documental como um todo (FLORES; PRADEBON; CÉ, 2017).

Com isso, a perspectiva holística advinda do Records Continuum consolida a interdependência entre as cadeias de custódia e de preservação. Ademais, deve-se pensar em preservar antes mesmo de se produzir documentos, igualmente, é preciso que tal pensamento seja reforçado durante a tramitação, a fim de garantir a manutenção da autenticidade e o acesso ininterrupto.

\section{CONSIDERAÇÕES FINAIS}

Este estudo realizou uma análise da relação entre a cadeia de preservação e a cadeia de custódia no âmbito da Arquivística. Para tanto, foram perpassadas questões como: a autenticidade em ambiente digital; fundamentos das cadeias de custódia e de preservação; o ciclo de vida dos documentos; e a perspectiva do Records Continuum. Foram abordadas questões que circundam a preservação de documentos arquivísticos digitais, como a custódia ininterrupta 
e a necessidade de se implementar sistemas informatizados.

Os documentos arquivísticos produzidos e armazenados em ambiente digital são vulneráveis, de modo que sua autenticidade e sua capacidade probatória podem ser facilmente abaladas. Para minimizar tais riscos, deve-se implementar sistemas informatizados que contemplem todo o ciclo de vida destes documentos. Assim, ambienconvencionou-se implementar: um SIGAD em conformidade com o modelo e-Arq Brasil no ambiente de gestão; e um RDCArq em conformidade com o modelo OAIS no ambiente de preservação.

Ao se considerar estes dois ambientes distintos (gestão e preservação), porém sequenciais, ressalta-se a importância de manter níveis de interoperabilidade entre as plataformas do SIGAD e do RDC-Arq. Com isso, o SIGAD irá montar SIPs que serão recolhidos ao RDC-Arq, de modo que haverá compatibilidade entre os metadados e formatos de arquivos dos materiais que se desejam preservar.

Será necessário dispor de infraestrutura organizacional, tecnológica e de segurança para viabilizar a manutenção da autenticidade dos documentos arquivísticos digitais. Isso poderá ser realizado por meio de uma cadeia de custódia ininterrupta, que une o ciclo de vida dos documentos, envolvendo assim, O SIGAD e o RDC-Arq. Consequentemente, devem-se respeitar as especificidades advindas da teoria arquivística, bem como compreender e se adequar às complexidades da informação digital.

Observa-se que a cadeia de custódia e a cadeia de preservação possuem elevado nível de interdependência quando abordadas em ambiente digital. Isto se deve ao fato dos documentos arquivísticos digitais possuírem uma série de vulnerabilidades implícitas à sua natureza. Tão logo, a preservação precisa estar presente em todo o ciclo de vida, não podendo se limitar aos arquivos permanentes. Além disso, a custódia ininterrupta/contínua precisa estar presente para agregar confiabilidade ao sistema de arquivo, a fim de manter a autenticidade dos documentos, tanto na perspectiva custodial, quanto na póscustodial.

Se desperta a atenção para a necessidade de interligar os ambientes que compõe o sistema de informação, ou seja, os sistemas de negócio (ERP, CRM 
e outros), o SIGAD e o RDC-Arq. A interoperabilidade entre tais ambientes otimiza os fluxos de informação, os quais devem ser envolvidos pelas cadeias de custódia e preservação.

Ao abordar o modelo Records Continuum, identificaram-se convergências com a manutenção das cadeias de custódia e preservação. A não linearidade do ciclo de vida retrata as necessidades dos documentos digitais, que requerem uma postura de preservação pró-ativa, tendo em vista a constante evolução das tecnologias da informação. Tal cenário favorece a implementação de estratégias de preservação e padrões de metadados, com essas ações será possível mitigar os efeitos da obsolescência tecnológica e prevenir perdas de informação.

O Records Continuum permite compreender a importância da manutenção pró-ativa dos documentos digitais dadas as suas complexidades e vulnerabilidades. Com isso, pode-se vislumbrar a interdependência das cadeias de custódia e preservação atuando em prol da preservação e garantia de acesso em longo prazo. Embora essa abordagem seja produto do conjunto de teorias e práticas advindas da Austrália, há elementos que podem ser incorporados ou adaptados para outros contextos geopolíticos, como por exemplo, o brasileiro.

No Brasil, a arquivística tradicional firmou-se como uma prática préconcebida que vem sistematicamente sendo influenciada pela arquivística integrada, de modo que passa a delegar a mesma importância para os arquivos correntes, intermediários e permanentes. Igualmente, o Records Continuum poderá trazer contribuições à arquivística que é praticada.

Entretanto, não se trata de uma disputa por hegemonia junto às correntes tradicional e integrada, e sim de um processo de reformulação epistemológica e pragmática que tende a influenciar o modus operandi da Arquivística. Portanto, acredita-se que a complexidade dos contextos geopolíticos não permite alternar entre os modelos praticados (tradicional, integrada, Records management e Records Continuum). No entanto, as correntes arquivísticas podem influenciar umas às outras, bem como podem ser adaptadas conforme o contexto geopolítico.

Quando se pensa na preservação de documentos arquivísticos em ambiente digital, o modelo Records Continuum se mostra mais eficaz para 
contornar os entraves da obsolescência. Ademais, é preciso pensar nas cadeias de custódia e preservação de forma sincronizada, pois o ambiente digital tornaas interdependentes.

Por fim, este estudo contribuiu para expandir o conhecimento em relação à preservação de documentos arquivísticos digitais. Com isso, foi possível despertar a atenção para a interdependência entre a cadeia de custódia e a cadeia de preservação. Ademais, permite incentivar o diálogo em torno do modelo Records Continuum, ressaltando os benefícios de sua visão holística para a preservação digital. Acredita-se que a intervenção pró-ativa no sistema de arquivos contribui para o êxito da preservação, da manutenção da autenticidade e da garantia de acesso em longo prazo.

\section{REFERÊNCIAS}

ASSOCIAÇÃO BRASILEIRA DE NORMAS TÉCNICAS (ABNT). NBR 15472: 2007. Sistemas espaciais de dados e informações - Modelo de referência para um sistema aberto de arquivamento de informação (SAAI). Rio de Janeiro: ABNT, 2007.

BELLOTTO, H. L. Arquivística: objetos, princípios e rumos. São Paulo: Associação de Arquivistas de São Paulo, 2002.

BRASIL. ARQUIVO NACIONAL DO. Dicionário brasileiro de terminologia arquivística (DBTA). Rio de Janeiro: Arquivo Nacional, 2005. Disponível em: http://www.arquivonacional.gov.br/images/pdf/Dicion_Term_Arquiv.pdf. Acesso em: 23 mar. 2020.

BRASIL. CONSELHO NACIONAL DE ARQUIVOS (CONARQ). Câmara Técnica de Documentos Eletrônicos (CTDE). Diretrizes para a implementação de repositórios arquivísticos digitais confiáveis - RDCArq. Rio de Janeiro: Arquivo Nacional, 2015. Disponível em: http://www.conarq.gov.br/images/publicacoes_textos/diretrizes_rdc_arq.pdf. Acesso em: 23 mar. 2020.

BRASIL. CONSELHO NACIONAL DE ARQUIVOS (CONARQ). Câmara Técnica de Documentos Eletrônicos (CTDE). Glossário: Documentos Arquivísticos Digitais. v. 4. Rio de Janeiro: CTDE, 2008. Disponível em: http://conarq.arquivonacional.gov.br/images/ctde/Glossario/2016-CTDEGlossario_V7_public.pdf. Acesso em: 23 mar. 2020.

BRASIL. CONSELHO NACIONAL DE ARQUIVOS (CONARQ). Câmara Técnica de Documentos Eletrônicos (CTDE). e-ARQ Brasil: Modelo de 
Requisitos para Sistemas Informatizados de Gestão Arquivística de Documentos. Rio de Janeiro: Arquivo Nacional, 2011a. Disponível em: http://www.siga.arquivonacional.gov.br/images/publicacoes/e-arq.pdf. Acesso em: 23 mar. 2020.

BRASIL. CONSELHO NACIONAL DE ARQUIVOS (CONARQ). Câmara Técnica de Documentos Eletrônicos (CTDE). Orientação Técnica n. $\mathbf{0} 1$ de abril de 2011 - orientações para contratação de SIGAD e serviços correlatos. Rio de Janeiro: CTDE, 2011b. Disponível em: http://conarq.arquivonacional.gov.br/images/ctde/Orientacoes/Orientacao_tecni ca_1.pdf. Acesso em: 23 mar. 2020.

BRASIL. CONSELHO NACIONAL DE ARQUIVOS (CONARQ). Câmara Técnica de Documentos Eletrônicos (CTDE). Diretrizes para a presunção de autenticidade de documentos arquivísticos digitais. Rio de Janeiro: Arquivo Nacional, 2012. Disponível em:

http://conarq.gov.br/images/publicacoes_textos/conarq_presuncao_autenticidad e_completa.pdf. Acesso em: 23 mar. $20 \overline{20}$.

BRASIL. CONSELHO NACIONAL DE ARQUIVOS (CONARQ). Câmara Técnica de Documentos Eletrônicos (CTDE). Diretrizes para a implementação de repositórios arquivísticos digitais confiáveis - RDCArq. Rio de Janeiro: Arquivo Nacional, 2015. Disponível em: http://www.conarq.gov.br/images/publicacoes_textos/diretrizes_rdc_arq.pdf. Acesso em: 23 mar. 2020.

CONSULTATIVE COMMITTEE FOR SPACE DATA SYSTEM (CCSDS). Reference Model for an Open Archival Information System (OAIS). Magenta Book. Washington: CCSDS, 2012. Disponível em: http://public.ccsds.org/publications/archive/650x0m2.pdf. Acesso em: 23 mar. 2020.

CORDEIRO, A. M.; OliveiRA, G. M.; RENTERÍA, J. M.; GUIMARÃES, C. A. Revisão sistemática: uma revisão narrativa. Rev. Col. Bras. Cir., Rio de Janeiro, v. 34, n. 6, p. 428-431, 2007. Disponível em: http://dx.doi.org/10.1590/S0100-69912007000600012. Acesso em: 23 mar. 2020.

COSTA, E. S. A descrição arquivística e a recuperação da informação na proposta de um modelo conceitual de sistemas informatizados de gestão arquivística de documentos: um estudo em instituições de ensino superior. Tese (Doutorado em Ciência da Informação). Universidade Estadual Paulista (UNESP). Marília: UNESP, 2018. Disponível em: https://repositorio.unesp.br/handle/11449/153808. Acesso em: 23 mar. 2020.

DURANTI, L. Diplomática: novos usos para uma antiga ciência (parte V). Acervo, Rio de Janeiro, v. 28, n.1, p. 196-215, 2015. Disponível em: 
https://www.brapci.inf.br/index.php/res/download/108712. Acesso em: 23 mar. 2020.

EASTWOOD, T.; HOFMAN, H.; PRESTON, R. Modeling Digital Records Creation, Maintenance and Preservation: Modeling Cross-domain Task Force Report. In: DURANTI, L.; PRESTON, R. (Org.). International Research on Permanent Authentic Records in Electronic Systems (InterPARES) 2: Experiential, Interactive and Dynamic Records. Padova, Italy: Associazione Nazionale Archivistica Italiana, 2008.

FLORES, D.; PRADEBON, D. S.; CÉ, G. Análise do conhecimento teóricometodológico da preservação digital sob a ótica da OAIS, SAAI, ISO 14721 e NBR 15472. Brazilian Journal of Information Science: research trends, v. 11, n. 4, p. 72-80 2017. Disponível em: https://doi.org/10.36311/19811640.2017.v11n4.11.p73. Acesso em: 23 mar. 2020.

FLORES, D.; ROCCO, B. C. B.; SANTOS, H. M. Cadeia de custódia para documentos arquivísticos digitais. Acervo, Rio de Janeiro, v. 29, n. 2, p. 117132, 2016. Disponível em:

http://www.brapci.inf.br/index.php/res/download/53277. Acesso em: 23 mar. 2020.

GIL, A. C. Como elaborar projetos de pesquisa. 4. ed. São Paulo: Atlas, 2010.

INNARELLI, H. C. Gestão da preservação de documentos arquivísticos digitais: proposta de um modelo conceitual. Tese (Doutorado em Ciência da Informação). Universidade de São Paulo (USP). São Paulo: USP, 2015. https://www.teses.usp.br/teses/disponiveis/27/27151/tde-27052015101628/publico/HumbertoCelestelnnarelliVC.pdf. Acesso em: 23 mar. 2020.

INTERNATIONAL ORGANIZATION FOR STANDARDIZATION. ISO 14721:2012. Space data and information transfer systems: open archival information system - Reference model. Genebra: ISO, 2012.

INTERNATIONAL RESEARCH ON PERMANENT AUTHENTIC RECORDS IN ELECTRONIC SYSTEMS (INTERPARES 2 PROJECT). Diretrizes do Produtor. A elaboração e a manutenção de materiais digitais: diretrizes para indivíduos. TEAM Brasil. Tradução: Arquivo Nacional e Câmara dos Deputados. 2007b. Disponível em:

http://www.siga.arquivonacional.gov.br/images/publicacoes/diretrizes_produtor_ digital.pdf. Acesso em: 23 mar. 2020.

INTERNATIONAL RESEARCH ON PERMANENT AUTHENTIC RECORDS IN ELECTRONIC SYSTEMS (INTERPARES 2 PROJECT). Diretrizes do Preservador. A preservação de documentos arquivísticos digitais: diretrizes para organizações. TEAM Brasil. Tradução: Arquivo Nacional e Câmara dos Deputados. 2007a. Disponível em: 
http://www.interpares.org/display_file.cfm?doc=ip2_preserver_guidelines_bookl et--portuguese.pdf. Acesso em: 23 mar. 2020.

JENKINSON, $\mathrm{H}$. A manual of archive administration including the problems of war archives and archive making. Oxford: Clarendon Press, 1922.

LUNA, S. V. Planejamento de pesquisa: uma introdução. São Paulo: EDUC, 1997.

LUZ, C. S. Curadoria digital, custódia arquivística e preservação digital: relações possíveis. Páginas a\&b. v. 3, n.o 10, p. 92-103, 2018. Disponível em: https://doi.org/10.21747/21836671/pag10a7. Acesso: 23 mar. 2020.

LUZ, Charlley; FLORES, Daniel. Cadeia de custódia e de preservação: autenticidade nas plataformas de gestão e preservação de documentos arquivístico. In: SEMINÁRIO SERVIÇOS DE INFORMAÇÃO EM MUSEUS, 4., 2016, São Paulo. Anais [...] São Paulo: Pinateca de São Paulo, 2016. Disponível em: https://www.researchgate.net/publication/325225229. Acesso: 23 mar. 2020.

MACNEIL, H. Correntes em transformação. In: EASTWOOD, T.; MACNEIL, H. (Org.). Correntes atuais do pensamento arquivístico. Belo Horizonte: Editora UFMG, 2016. p. 7-16.

\section{MÁRDERO ARELLANO, M. Á. Critérios para a preservação digital da} informação científica. Tese (Doutorado em Ciência da Informação). Universidade Federal de Brasília (UnB). Brasília: UnB, 2008. Disponível em: https://repositorio.unb.br/handle/10482/1518. Acesso em: 23 mar. 2020.

RODRIGUES, A. M. L. Uma análise da teoria dos arquivos. Dissertação (Mestrado em Ciência da Informação). Universidade Federal de Minas Gerais (UFMG). Minas Gerais: UFMG, 2004. Disponível em:

http://hdl.handle.net/1843/LHLS-69UR3J. Acesso em: 23 mar. 2020.

ROGERS, C. A literature review of authenticity of records in digital systems: from 'machine-readable' to records in the cloud. Acervo, Rio de Janeiro, v. 29, n. 2, p. 16-44, 2016. Disponível em: http://revista.arquivonacional.gov.br/index.php/revistaacervo/article/view/715. Acesso em: 23 mar. 2020.

RONDINELLI, R. C. O conceito de documento arquivístico frente à realidade digital: uma revisitação necessária. Tese (Doutorado em Ciência da Informação). Universidade Federal Fluminense (UFF). Niterói: UFF, 2011. Disponível em:

https://www.siarq.unicamp.br/siarq/images/siarq/publicacoes/preservacao_digit al/tese_rondinelli.pdf. Acesso em: 23 mar. 2020. 
RONDINELLI, R. C. $O$ documento arquivístico ante a realidade digital: uma revisão conceitual necessária. Rio de Janeiro: FGV, 2013.

SANTOS, H. M.; FLORES, D. As vulnerabilidades dos documentos digitais: Obsolescência tecnológica e ausência de políticas e práticas de preservação digital. Biblios: Revista de Bibliotecología y Ciencias de la Información, Lima/Brasília, n. 59, p. 45-54, 2015. Disponível em:

https://doi.org/10.5195/biblios.2015.215. Acesso em: 23 mar. 2020.

SANTOS, H. M.; FLORES, D. Preservação do patrimônio documental arquivístico em ambiente digital. Palabra Clave, La Plata, v. 7, n. 1, 2017. Disponível em: https://doi.org/10.24215/18539912e029. Acesso em: 23 mar. 2020.

SILVA, E. L.; MENEZES, E. M. Metodologia da pesquisa e elaboração de dissertação. 4. ed. rev. atual. Florianópolis: UFSC, 2005. Disponível em: http://www.portaldeconhecimentos.org.br/index.php/por/Conteudo/Metodologiada-pesquisa-e-elaboracao-de-dissertacao. Acesso em: 23 mar. 2020.

SILVA, M. $\mathbf{O}$ arquivo e lugar: a custódia arquivística como responsabilidade pela proteção aos arquivos. Tese (Doutorado em História Social). Universidade de São Paulo (USP). São Paulo: USP, 2015. Disponível em: https://doi.org/10.11606/T.8.2015.tde-22122015-093801. Acesso em: 23 mar. 2020.

SILVA, M. O arquivo e o lugar: custódia arquivística e a responsabilidade pela proteção aos arquivos. Niterói: Eduff, 2017.

SOUZA, J. F.; SOARES, M. A.; FERNANDES, J. N.; MELO, J. H. Gestão de documentos digitais na cidade viva: uma proposta de uso do archivematica como repositório para recolhimento de objetos digitais permanentes. Archeion Online, v. 5, p. 84-102, 2017. Disponível em: http://dx.doi.org/10.22478/ufpb.2318-6186.2017v5n4.36248. Acesso em: 23 mar. 2020.

THOMAZ, K. P. A preservação de documentos eletrônicos de caráter arquivístico: novos desafios, velhos problemas. Tese (Doutorado em Ciência da Informação). Universidade Federal de Minas Gerais (UFMG). Belo Horizonte: UFMG, 2004. Disponível em:

https://repositorio.ufsc.br/handle/123456789/87640. Acesso em: 23 mar. 2020.

UPWARD, F. Structuring the Records Continuum - Part Two: Structuration theory and recordkeeping. Archives and Manuscripts, Sydney, v. 25, n. 1, pt. 2, p. 10-35, 1997. Disponível em: https://publications.archivists.org.au/index.php/asa/article/view/8613. Acesso em: 23 mar. 2020. 
VOLPATO, G. L.; BARRETO, R. E.; UENO, H. M.; VOLPATO, E. D. S. N.; GIAQUINTO, P. C.; FREITAS, E. G. D. Dicionário crítico para redação científica. Botucatu: Best Writing, 2013.

VOUTSSÁS MÁRQUEZ, J. La cadena de preservación en archivos digitales. In: BARNARD, A. A. (Org.). Archivos electrónicos: Textos y contextos. México: Red Nacional de Archivos de Educación Superior y Archivo Histórico de la Universidad Nacional Autónoma de Puebla, 2010. p. 143-167.

\title{
TRUSTED DIGITAL ENVIRONMENTS FOR HOLISTIC PRESERVATION OF ARCHIVAL RECORDS
}

\begin{abstract}
Introduction: This study addresses the issue of archival records in a digital environment, which are endowed with complexities and specificities that directly impact preservation and access. Therefore, they need reliable systems that guarantee their probative capacity, so that they can be used as evidence. Objective: Therefore, the relationship between the chains of custody and preservation is discussed, with a view to building a reliable environment capable of preserving archival records and maintaining their authenticity in long term with guaranteed access. Methodology: For this purpose, a bibliographic survey was carried out, consisting essentially of books, technical publications, theses and scientific articles retrieved through the Google Scholar search tool. It seeks to explain the interdependence between the chains of custody and preservation, have the Records Continuum model as a backdrop. You get a review article no systematic/narrative. Results: It was observed that the chains of custody and preservation have a high level of interdependence when addressed in a digital environment. Thus, there is a need to maintain an uninterrupted line between the Computerized Archival Record Management System and the Trusted Digital Archival Repository. Likewise, preservation actions must be thought of in management and even before record production, this assumption converges with the foundations of Records Continuum. Conclusions: Therefore, the interdependence of chains of custody and preservation coupled with the need to proactively preserve records points to a reformulation of the collections. This requires holistic documentary treatment, capable of preventing and minimizing the effects of technological obsolescence.
\end{abstract}

Descriptors: Digital preservation. Reliability. Documentary chain of custody. Documentary chain of preservation.

\section{ENTORNOS DIGITALES DE CONFIANZA PARA LA PRESERVACIÓN HOLÍSTICA DE DOCUMENTOS ARCHIVÍSTICOS}

\section{RESUMEN}

Introducción: Este estudio aborda el tema de los documentos de archivo en un entorno digital, dotados de complejidades y especificidades que impactan directamente la preservación y el acceso. Por lo tanto, necesitan sistemas confiables que garanticen su 
capacidad probatoria, de modo que puedan usarse como evidencia. Objetivo: Por lo tanto, se discute la relación entre las cadenas de custodia y preservación, con miras a construir un entorno confiable capaz de preservar documentos de archivo y mantener su autenticidad a largo plazo con acceso garantizado. Metodología: Para este propósito, se realizó una encuesta bibliográfica, que consistió esencialmente en libros, publicaciones técnicas, tesis y artículos científicos recuperados a través de la herramienta de búsqueda de Google Scholar. Busca explicar la interdependencia entre las cadenas de custodia y preservación, teniendo el modelo de Records Continuum como telón de fondo. Usted obtiene un artículo de revisión no sistemática/narrativa. Resultados: Se observó que las cadenas de custodia y preservación tienen un alto nivel de interdependencia cuando se abordan en un entorno digital. Por lo tanto, existe la necesidad de mantener una línea ininterrumpida entre el Sistema de Gestión de Documentos de Archivo Informatizados y el Repositorio de Archivos Digitales de Confianza. Del mismo modo, las acciones de preservación deben considerarse en la gestión e incluso antes de la producción de documentos, esta suposición converge con los fundamentos de Records Continuum. Conclusiones: Por lo tanto, la interdependencia de las cadenas de custodia y preservación, junto con la necesidad de preservar proactivamente los documentos, apunta a una reformulación de las colecciones. Esto requiere un tratamiento documental holístico, capaz de prevenir y minimizar los efectos de la obsolescencia tecnológica.

Descriptores: Preservación digital. Fiabilidad. Cadena de custodia documental. Cadena de preservación de documentos.

Recebido em:24.03.2020

Aceito em:14.09.2020 